\title{
Bone-patellar tendon-bone autografts versus hamstring autografts for reconstruction of anterior cruciate ligament: meta-analysis
}

\author{
David J Biau, Caroline Tournoux, Sandrine Katsahian, Peter J Schranz, Rémy S Nizard
}

\begin{abstract}
Objectives To compare bone-patellar tendon-bone autografts with hamstring autografts for reconstruction of the anterior cruciate ligament.

Data sources Medline, WebSPIRS, Science Citation Index, Current Contents databases, and Cochrane Central Register of Controlled Trials.

Review methods All randomised controlled trials reporting one or more outcome related to stability (instrumented measurement of knee laxity, Lachman test, or pivot shift test) and morbidity (anterior knee pain, kneeling test, loss of extension, or graft failure). Study quality was assessed by using a 5 point scale. Random effect models were used to pool the data. Heterogeneity in the effect of treatment was tested on the basis of study quality, randomisation status, and number of tendon strands used.

Results 24 trials of 18 cohorts (1512 patients) met the inclusion criteria. Study quality was poor for nine studies and fair for nine studies. The weighted mean difference of the instrumented measurement of knee laxity was 0.36 (95\% confidence interval 0.01 to $0.71 ; \mathrm{P}=0.04)$. Relative risk of a positive Lachman test was 1.22 (1.01 to $1.47 ; \mathrm{P}=0.04)$, of anterior knee pain 0.57 (0.44 to $0.74 ; \mathrm{P}<0.0001)$, of a positive kneeling test $0.26(0.14$ to $0.48 ; \mathrm{P}<0.0001)$, and of loss of extension 0.52 (0.34 to 0.80 ; $\mathrm{P}=0.003)$. Other results were not significant.

Conclusion Morbidity was lower for hamstring autografts than for patellar tendon autografts. Evidence that patellar tendon autografts offer better stability was weak. The poor quality of the studies calls into question the robustness of the analyses.
\end{abstract}

\section{Introduction}

The incidence of anterior cruciate ligament tears in the United States is 0.38 per 1000 each year. ${ }^{1}$ In the US in 1996, doctors repaired this ligament in more than 100000 patients (72000 outpatients and 35300 inpatients). ${ }^{2}$ Expectations of preventing meniscal and chondral damage and a return to the level of activity before injury are high. ${ }^{3}$

The best choice of graft for reconstruction is debatable. ${ }^{4}$ The bone-patellar tendon-bone autograft (the criterion standard) is still preferred to the newer hamstring tendon autograft for the first reconstruction..$^{5-7}$ Patellar tendon grafts are thought to offer better stability, but hamstring grafts have lower morbidity. Randomised clinical trials show contradictory results. ${ }^{8 \text { w1-w24 }}$ Two meta-analyses, one of four and one of six randomised or quasi-randomised clinical trials, could not clarify the results of most outcomes. ${ }^{9}{ }^{10}$
Most surgeons perform only one type of reconstruction at first surgery. ${ }^{11}$ Therefore, the choice of surgeon made by the referring general practitioner decides the type of graft and the outcomes the patient will benefit.

We performed a meta-analysis to compare the two types of autografts for reconstruction of the anterior cruciate ligament to provide up to date knowledge for doctors who have to decide between the two transplants with regard to stability and morbidity.

\section{Methods}

Search strategy

We searched Medline, WebSPIRS, Science Citation Index, Current Contents databases, and Cochrane Central Register of Controlled Trials up to 14 March 2005; we also cross checked the reference lists of published trials (search terms are on bmj.com). We had no restrictions on date of publication, language, or publication status. In addition, we sent a copy of selected studies (all randomised controlled trials that compared the two treatments, with no restrictions regarding outcome or follow-up time) to all authors of these studies, main and specialised orthopaedic journals, and organisations with an interest in the topic to ask if they knew of any other published or unpublished trials. The closing date for retrieving studies and additional data was 14 May 2005.

Trials selection and study characteristics

We selected trials that were randomised or quasi-randomised (providing groups had been set up over the same period), included patellar tendon and hamstring autograft reconstruction without augmentation in the comparison, had a mean follow-up of more than one year, and had one or more primary outcome related to stability (instrumented measurement of knee laxity, Lachman test, or pivot shift test) and morbidity (anterior knee pain, kneeling test, loss of extension, or graft failure) (see appendix A on bmj.com for a description of the most often used tests). ${ }^{12}$

\section{Data abstraction and assessment of validity}

Two of the authors (DJB and CT) independently extracted data on study design, setting, population, condition of interest, interventions and co-interventions, outcomes, and the quality of the studies by using standardised forms. Disagreements were resolved by discussion and if necessary with the help of other authors (SK and RSN). All authors of the selected studies were contacted if necessary to retrieve relevant unpublished data. The

Additional references w1-w24, details of the outcome tests (appendix A), the five point quality score (appendix B), and the search items appear on bmj.com 


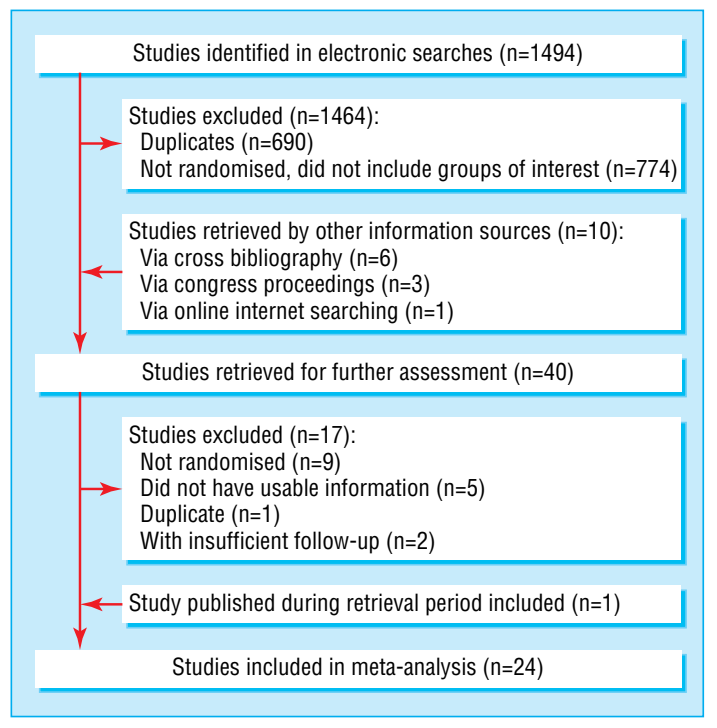

Fig 1 Selection process for meta-analysis of trials to compare bone-patellar tendon-bone autografts with hamstring autografts for reconstruction of the anterior cruciate ligament

quality of the studies was scored on a five point scale (appendix B on bmj.com).

\section{Quantitative data synthesis}

We entered eligible trials into RevMan 4.2.7 software (Cochrane Collaboration) and sorted them according to inclusion and exclusion criteria. Results of the Lachman test $(0 v \geq 1)$, pivot shift test ( $0 v \geq 1$ ), anterior knee pain (no $v$ yes), kneeling test (pain or impossible $v$ no pain or possible), extension loss $\left(<5^{\circ} v\right.$ $\geq 5^{\circ}$ ), and graft failure (no $v$ yes; failures due to infection were excluded) were treated as binary variables. The results of instrumented measurement of knee laxity were treated as continuous variables. We used RevMan Analysis Software (version 1.0.2) with a random effects model to analyse data. We used the $\chi^{2}$ to test for heterogeneity between trials; $\mathrm{P} \leq 0.1$ indicated significant heterogeneity.

To look for variation in the effect of treatment based on study quality (score of $<3 \quad v \geq 3$ ), randomisation status (quasirandomised $v$ randomised), and number of strands used in the hamstring tendon group ( $<4 v 4$ strands), we performed quantitative interaction tests. We performed subgroup analysis to assess the size of the effect of treatment on stability outcomes for studies with only a four strand hamstring autograft in the treatment group.

\section{Results}

\section{Eligible studies}

The search strategy generated 1494 studies. Twenty four studies were relevant according to the title, abstract, and complete retrieval of the article (fig 1). ${ }^{\text {w1-w24 }}$ We contacted nine authors to retrieve additional data and clarify possible overlap of patients; seven provided useful information. ${ }^{\text {w9 }}$ w10 w14 w17 w18 w22 w24

When data in studies overlapped, we merged them by outcome to have the longest follow-up and then the most patients included. Finally, 18 merged cohort studies were analysed; three studies had three treatment groups. ${ }^{\text {w4 }}$ w18 w21 Groups that were of no interest were excluded from the analysis, ${ }^{\mathrm{w} 4}$ and others were pooled. ${ }^{\mathrm{w} 18 \mathrm{w} 21}$

\section{Study characteristics}

The studies were published between 1991 and 2005, and analysed 1512 patients (765 in the control group and 747 in the hamstring group). Patients had mean ages of 22-31 (11

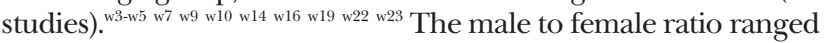
from 1.1 to men only (12 studies). ${ }^{\text {w3-w5 }}$ w7 w9 w10 w14 w18 w19 w21-w23 Follow-up ranged from 12 to 102 months, with a mean of 36 months (table 1).

All patients in the control group received a patellar tendon autograft. In the treatment group, a four strand hamstring autograft was used in 10 studies, ${ }^{\text {w2 }}$ w3 w5 w6 w10 w14 w16 w17 w19 w23 a four or a three strand autograft in two studies, ${ }^{\text {w9 }}{ }^{\text {w18 }}$ a two strand

Table 1 Details of trials of bone-patellar tendon-bone autografts versus hamstring autografts for reconstruction of the anterior cruciate ligament

\begin{tabular}{|c|c|c|c|c|c|c|c|c|c|c|c|}
\hline \multirow[b]{2}{*}{ Study } & \multirow{2}{*}{$\begin{array}{c}\text { Date of } \\
\text { publication }\end{array}$} & \multirow{2}{*}{$\begin{array}{c}\text { Mean } \\
\text { age of } \\
\text { patients }\end{array}$} & \multirow[b]{2}{*}{$\begin{array}{c}\text { Sex ratio } \\
\text { (M:F) }\end{array}$} & \multirow{2}{*}{$\begin{array}{l}\text { No of patients } \\
\text { analysed }\end{array}$} & \multirow{2}{*}{$\begin{array}{c}\text { Mean } \\
\text { follow-up } \\
\text { (months) }\end{array}$} & \multirow[b]{2}{*}{$\begin{array}{l}\text { No of HS } \\
\text { strands }\end{array}$} & \multicolumn{2}{|c|}{ Patellar tendon } & \multicolumn{2}{|c|}{ Hamstring } & \multirow{2}{*}{$\begin{array}{l}\text { Overall } \\
\text { quality of } \\
\text { study }\end{array}$} \\
\hline & & & & & & & $\begin{array}{l}\text { Femoral } \\
\text { fixation }\end{array}$ & $\begin{array}{c}\text { Tibial } \\
\text { fixation }\end{array}$ & $\begin{array}{l}\text { Femoral } \\
\text { fixation* }\end{array}$ & $\begin{array}{c}\text { Tibial } \\
\text { fixation }\end{array}$ & \\
\hline Aglietti (2) $)^{\star w 1 ~ w 2 ~}$ & 1997 & NA & NA & 60 & 68 & 4 & $\mathrm{Sc}+\mathrm{W}$ & $\mathrm{ISc}+\mathrm{Sc}+\mathrm{W}$ & $\mathrm{Sc}+\mathrm{W}$ & $\mathrm{Sc}+\mathrm{W}( \pm \mathrm{St})$ & 3 \\
\hline Aglietti w3 & 2004 & 25 & 5.1 & 120 & 24 & 4 & TcSc & ISc & TcSc & WL & 3 \\
\hline Anderson $^{w 4}$ & 2001 & 22 & 1.5 & 68 & 35 & 2 & ISC & St & St & $\mathrm{Su}$ & 3 \\
\hline Aune $^{\text {w5 }}$ & 2001 & 26 & 1.1 & 61 & 24 & 4 & ISC & ISC & EB & $\mathrm{ISc}+\mathrm{St}$ & 4 \\
\hline Beardw6 $^{\text {w6 }}$ & 2001 & NA & NA & 45 & 12 & 4 & ISc & ISC & ISC & ISC & 2 \\
\hline Beynnon $^{w 7}$ & 2002 & 29 & 1.2 & 44 & 36 & 2 & ISC & ISC & St & St & 2 \\
\hline Callaway ${ }^{\text {w8 }}$ & 1997 & NA & NA & 95 & 34 & NA & NA & NA & NA & NA & 1 \\
\hline Ejerhed $^{\text {w9 }}$ & 2003 & 28 & 2.3 & 66 & 24 & 3 and 4 & ISC & ISC & ISC & ISC & 4 \\
\hline $\begin{array}{l}\text { Eriksson }(2)^{\star w 10} \\
\text { w11 }\end{array}$ & 2001 & 26 & 1.4 & 154 & 33 & 4 & ISC & ISC & EB & $\mathrm{Sc}+\mathrm{W}$ & 3 \\
\hline 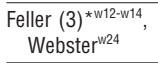 & 2003 & 26 & 2.6 & 57 & 36 & 4 & $E B$ & ISc & $\mathrm{EB}$ & $P$ & 4 \\
\hline Hantes $^{\text {w15 }}$ & 2004 & NA & NA & 45 & 12 & NA & NA & NA & NA & NA & 1 \\
\hline Ibrahimw16 & 2005 & 22 & Men only & 85 & 81 & 4 & EB & ISC & EB & $\begin{array}{l}\mathrm{Sc}+\mathrm{W} \text { or } \\
\mathrm{Pl}+\mathrm{Sc}+\mathrm{St}\end{array}$ & 1 \\
\hline Jansson ${ }^{\text {w17 }}$ & 2003 & NA & NA & 89 & 24 & 4 & ISC & ISC & $\mathrm{Pl}$ & $\mathrm{Sc}+\mathrm{W}$ & 2 \\
\hline Laxdal $^{w 18}$ & 2005 & NA & 2.0 & 118 & 24 & 3 and 4 & ISc & ISc & ISC & ISC & 4 \\
\hline Marder ${ }^{\mathrm{w} 19}$ & 1991 & 23 & 2.4 & 72 & 29 & 4 & $\mathrm{P}+\mathrm{W}$ & $\mathrm{P}+\mathrm{W}$ & $\mathrm{P}+\mathrm{W}$ & $\mathrm{P}+\mathrm{W}$ & 2 \\
\hline${\text { O’Neill }(2)^{* w 20 ~ w 21 ~}}$ & 2001 & NA & 2.0 & 225 & 102 & 2 & ISc & ISC & St & St & 2 \\
\hline Ropke w22 $^{\text {w22 }}$ & 2001 & 28 & 4.0 & 40 & 24 & 2 & ISC & ISC & EB & St & 3 \\
\hline Shaieb" ${ }^{\text {w23 }}$ & 2002 & 31 & 2.0 & 68 & 33 & 4 & ISC & ISc & ISC & ISC & 2 \\
\hline
\end{tabular}

$\mathrm{ISC}=$ interference screw, $\mathrm{EB}=$ =ndobutton, $\mathrm{NA}=$ data not available, $\mathrm{P}=$ post, $\mathrm{Pl}=$ plate, $\mathrm{Sc}=\mathrm{screw}, \mathrm{St}=$ staple, $\mathrm{Su}=$ sutures, TcSC=transcondylar screw, $\mathrm{W}=$ washer, $\mathrm{WL}=$ washerlock.

${ }^{*}$ No of studies with the same patients. 
Table 2 Outcome measures in meta-analysis of comparisons with patellar tendon autografts

2, 3, and 4 strand hamstring autografts

4 strand hamstring autografts

\begin{tabular}{|c|c|c|c|c|c|c|c|c|c|c|}
\hline Outcome & $\begin{array}{l}\text { Weighted mean difference } \\
\text { or relative risk }(95 \% \mathrm{CI})\end{array}$ & $P$ value & $\begin{array}{c}\text { Test for } \\
\text { heterogeneity }\end{array}$ & $\begin{array}{l}\text { No of } \\
\text { patients }\end{array}$ & $\begin{array}{l}\text { No of } \\
\text { studies }\end{array}$ & $\begin{array}{l}\text { Weighted mean } \\
\text { difference or relative } \\
\text { risk }(95 \% \mathrm{Cl})\end{array}$ & $P$ value & $\begin{array}{c}\text { Test for } \\
\text { heterogeneity }\end{array}$ & $\begin{array}{l}\text { No of } \\
\text { patients }\end{array}$ & $\begin{array}{l}\text { No of } \\
\text { studies }\end{array}$ \\
\hline IMKL $(89 \mathrm{~N})^{*}$ & 0.36 (0.01 to 0.71$) \mathrm{mm}$ & 0.04 & 0.84 & 448 & 5 & 0.28 ( -0.10 to 0.66$)$ & 0.15 & 0.96 & 332 & 3 \\
\hline $\begin{array}{l}\text { IMKL (maximum } \\
\text { manual force) }\end{array}$ & 0.70 (0.02 to 1.39$) \mathrm{mm}$ & 0.04 & 0.30 & 169 & 3 & 0.0 (-1.08 to 1.08$)$ & 1 & NA & 61 & 1 \\
\hline Lachman test† & 1.22 (1.01 to 1.47$)$ & 0.04 & 0.79 & 754 & 7 & 1.13 (0.85 to 1.50$)$ & 0.41 & 0.83 & 703 & 8 \\
\hline Pivot test† & 1.23 (0.95 to 1.60$)$ & 0.11 & 0.68 & 815 & 10 & 1.14 (0.89 to 1.47$)$ & 0.29 & 0.75 & 520 & 4 \\
\hline Loss of extension† & 0.52 (0.34 to 0.80$)$ & 0.003 & 0.67 & 920 & 7 & - & - & - & - & - \\
\hline $\begin{array}{l}\text { Anterior knee } \\
\text { paint }\end{array}$ & 0.57 (0.44 to 0.74$)$ & $<0.0001$ & 0.93 & 1011 & 12 & - & - & - & - & - \\
\hline Kneeling test† & 0.26 (0.14 to 0.48 ) & $<0.0001$ & 0.13 & 334 & 4 & - & - & - & - & - \\
\hline Graft failure $†$ & 1.33 (0.73 to 2.44$)$ & 0.35 & 0.99 & 1088 & 11 & - & - & - & - & - \\
\hline
\end{tabular}

*Weighted mean difference.

tRelative risk for the remainder.

IKML=instrumented measurement of knee laxity, $N A=$ not applicable.

autograft in four studies, ${ }^{\mathrm{w} 4}$ w7 w21 w22 and the number of strands used was unknown in two studies. ${ }^{\text {w }}{ }^{\text {w15 }}$ The use of arthroscopy

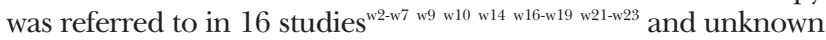
in two studies. ${ }^{18}$ w15 Preconditioning of the graft was reported in one study, ${ }^{\mathrm{w} 14}$ cycling in five studies, ${ }^{\mathrm{w} 3} \mathrm{w}^{5} \mathrm{w}^{2}$ w10 w21 securing under tension in eight studies, ${ }^{\mathrm{w} 2} \mathrm{w4}$ w5 $\mathrm{w} 7 \mathrm{w9} \mathrm{w10} \mathrm{w18}$ w19 and flexion degree of the knee when the graft was fixed in 12 studies. ${ }^{\text {w2-w6 }}$ w10 w11 w14 w16 w18 w19 w21 The type of femoral and tibial fixation varied greatly between studies. The programme of postoperative rehabilitation varied between studies but was similar for both groups in 17 studies. ${ }^{\mathrm{w} 2 \mathrm{w} 10} \mathrm{w} 14 \mathrm{w} 16-\mathrm{w} 19 \mathrm{w} 21-\mathrm{w} 23$

Study quality was poor in nine studies ${ }^{\mathrm{w} 6-\mathrm{w} 8} \quad \mathrm{w} 15-\mathrm{w} 17$ w19 $\mathrm{w} 21$ w23 (scored $\leq 2$ ) and fair in nine studies (scored 3 or 4). ${ }^{\mathrm{w} 2-\mathrm{w} 5} \mathrm{w} 9 \mathrm{w} 10 \mathrm{w} 14 \mathrm{w} 18$ ${ }^{\text {w22 }}$ No studies fulfilled all quality items (scored 5). The randomisation process was described and appropriate for six studies. ${ }^{\mathrm{w} 4}$ w6 ${ }^{\mathrm{w} 7 \mathrm{w9} \text { w14 w18 }}$ Six studies were quasi-randomised: in three allocation was based on alternation, ${ }^{\text {w2 } 23319}$ in two on date of birth, ${ }^{\text {w21 w23 }}$ and in one on the day of surgery. ${ }^{\text {w22 }}$ Withdrawal and dropout rates were acceptable for 13 studies, ${ }^{12-w 5}$ w9 w10 w14 w15 w17-w19 w21 w22

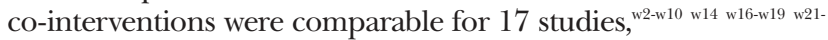

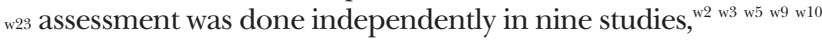
w14 w18 w22 w23 and intention to treat principle was referred to and adequate in one study. ${ }^{\mathrm{w} 5}$

\section{Quantitative data synthesis}

\section{Stability}

Table 2 shows the results of the meta-analysis of outcome measures. Analysis of the instrumented measurement of knee laxity was restricted to low force $(89 \mathrm{~N})$ and maximum manual testing. The difference in laxity between the operated side and the normal contralateral side was greater in the treatment group than in the control group (table 2). The instrumented measurement of knee laxity at $89 \mathrm{~N}$ was available for 239 patients in the treatment group and 209 patients in the control group in five studies. ${ }^{\mathrm{w} 6} \mathrm{w} 9 \mathrm{w} 10$ w18 w19 The weighted mean difference was $0.36 \mathrm{~mm}(95 \%$ confidence interval 0.01 to $0.71 ; \mathrm{P}=0.04$ ) and the test for heterogeneity was not significant $(\mathrm{P}=0.84)$ (fig 2$)$. Knee laxity at maximum manual force was available for 85 and 84 patients in the treatment and control groups in three studies. ${ }^{\mathrm{w} 4 \mathrm{w} 5}$ w22 The weighted mean difference was $0.70 \mathrm{~mm}(0.02$ to $1.39 ; \mathrm{P}=0.04)$ and the test for heterogeneity was not significant $(\mathrm{P}=0.30)$.

Data on the Lachman test were available for 754 patients in eight studies..$^{\mathrm{w} 37} \mathrm{w} 9 \mathrm{w} 10 \mathrm{w} 16 \mathrm{w} 17 \mathrm{w} 19 \mathrm{w} 21$ The test was positive in 122 of 355 patients in the treatment group (34\%) and 118 of 399 in the control group (30\%). The relative risk of a positive Lachman test was 1.22 (1.01 to $1.47 ; \mathrm{P}=0.04$ ). The test for heterogeneity was not significant $(\mathrm{P}=0.79)$ (fig 3$)$.

Data on the pivot shift test were available for 815 patients in 10 studies. $^{\mathrm{w} 2-\mathrm{w} 4}$ w7 $710 \mathrm{w} 14$ w16 $\mathrm{w} 17 \mathrm{w} 19 \mathrm{w} 23$ The test was positive in 99 of 411 patients in the treatment group (24\%) and 78 of 404 in the control group (19\%). The relative risk of a positive pivot shift test was 1.23 ( 0.95 to $1.6 ; \mathrm{P}=0.11)$. The test for heterogeneity was not significant $(\mathrm{P}=0.68)$.

\section{Morbidity}

Table 2 shows the results of the meta-analysis of outcome measures. Data on anterior knee pain were available for 1011 patients in 14 studies. ${ }^{\mathrm{w} 2} \mathrm{w} 3 \mathrm{w} 5 \mathrm{w} 7 \mathrm{- \textrm {w } 9} \mathrm{w} 10 \mathrm{w} 14-\mathrm{w} 16 \mathrm{w} 18 \mathrm{w} 19 \mathrm{w} 22 \mathrm{w} 23$ Anterior knee pain was reported in 69 of 536 patients in the treatment group (13\%) and 105 of 475 in the control group (22\%). The relative risk of anterior knee pain was $0.57(0.44$ to $0.74 ; \mathrm{P}<0.0001)$. The test for heterogeneity was not significant $(\mathrm{P}=0.93)$ (fig 4$)$.

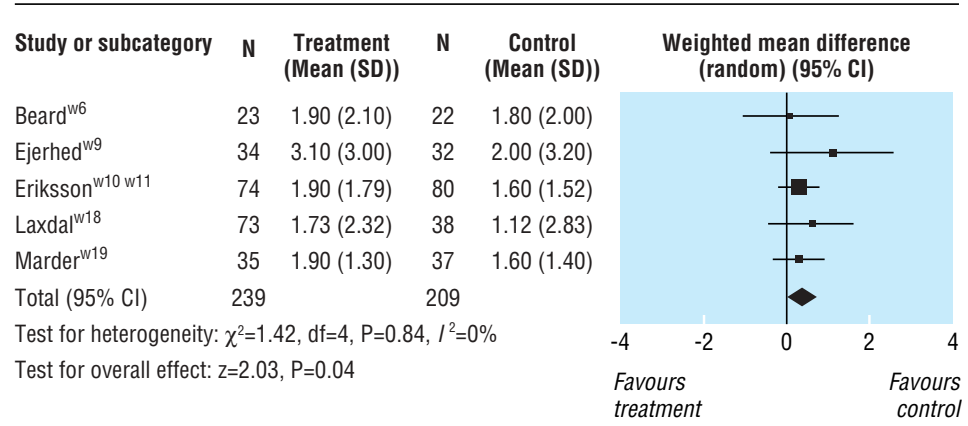

Fig 2 Instrumented measurement of knee laxity at 89N after reconstruction of anterior cruciate ligament. Treatment refers to hamstring autografts; control refers to bone-patellar tendon-bone autografts 


\begin{tabular}{|c|c|c|c|c|c|c|}
\hline Study or subcategory & $\begin{array}{l}\text { Treatment } \\
(\mathrm{n} / \mathrm{N})\end{array}$ & $\begin{array}{c}\text { Control } \\
(\mathrm{n} / \mathrm{N})\end{array}$ & & \multicolumn{2}{|c|}{$\begin{array}{c}\text { Relative risk } \\
\text { (random) }(95 \% \mathrm{CI})\end{array}$} & \\
\hline Agliettiw3 $^{\text {w3 }}$ & $0 / 60$ & $0 / 60$ & & & & \\
\hline Beynnonw7 & $19 / 22$ & $12 / 22$ & & & $\longrightarrow$ & \\
\hline Ejerhed $^{\text {w9 }}$ & $17 / 33$ & $14 / 32$ & & & & \\
\hline Eriksson ${ }^{w 10}$ w11 & $40 / 74$ & $40 / 80$ & & & & \\
\hline Ibrahimw16 & $7 / 45$ & $5 / 40$ & & & & \\
\hline Jansson ${ }^{w 17}$ & $8 / 46$ & $8 / 43$ & & & & \\
\hline Marderw19 & $17 / 35$ & $12 / 37$ & & & & \\
\hline O'Neill'w20 w21 & $14 / 40$ & $27 / 85$ & & & $=$ & \\
\hline Total $(95 \% \mathrm{Cl})$ & 355 & 399 & & & & \\
\hline \multicolumn{3}{|c|}{ Total events: 122 (treatment), 118 (control) } & 0.2 & 0.5 & 2 & 5 \\
\hline \multicolumn{3}{|c|}{ Test for heterogeneity: $\chi^{2}=3.16, \mathrm{df}=6, \mathrm{P}=0.79, I^{2}=0 \%$} & Fave & & & ours \\
\hline \multicolumn{3}{|c|}{ Test for overall effect: $z=2.10, P=0.04$} & treat & & & ntrol \\
\hline
\end{tabular}

Fig 3 Lachman test after reconstruction of the anterior cruciate ligament. Treatment refers to hamstring autografts; control refers to bone-patellar tendon-bone autografts

Data from the kneeling test were available for 334 patients in four studies. ${ }^{\text {w3 }}$ w14 w15 w18 The test was positive for 22 of 187 patients in the treatment group (12\%) and 75 of 147 in the control group (51\%). The relative risk of a positive kneeling test was $0.26(0.14$ to $0.48 ; \mathrm{P}<0.0001)$. The test for heterogeneity was not significant $(\mathrm{P}=0.13)$ (fig 5).

Data on loss of extension were available for 920 patients in

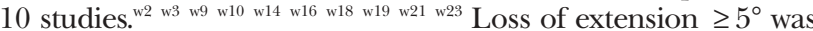

reported in 28 of 460 patients in the treatment group $(6 \%)$ and 43 of 460 in the control group $(9 \%)$. The relative risk of loss of extension was $0.52(0.34$ to $0.80 ; \mathrm{P}=0.003)$. The test for heterogeneity was not significant $(\mathrm{P}=0.67)$ (fig 6).

Data on graft failure were available for 1088 patients in 11

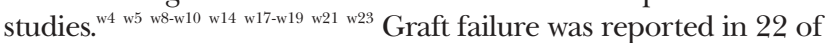
534 patients in the treatment group (4.1\%) and 19 of 554 patients in the control group $(3.4 \%)$. The relative risk of graft

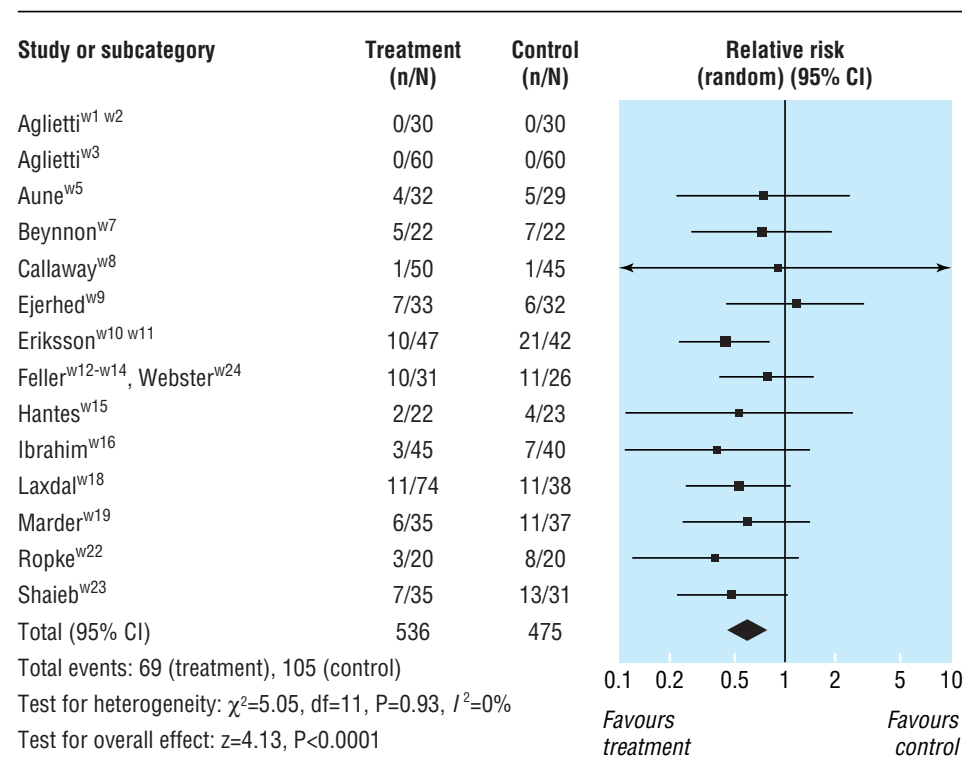

Fig 4 Anterior knee pain after reconstruction of the anterior cruciate ligament. Treatment refers to hamstring autografts; control refers to bone-patellar tendon-bone autografts

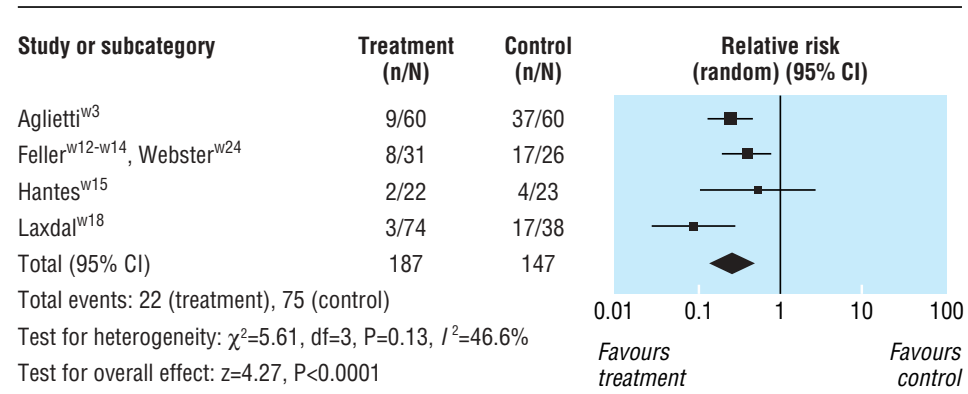

Fig 5 Results of kneeling test after reconstruction of the anterior cruciate ligament. Treatment refers to hamstring autografts; control refers to bone-patellar tendon-bone autografts 


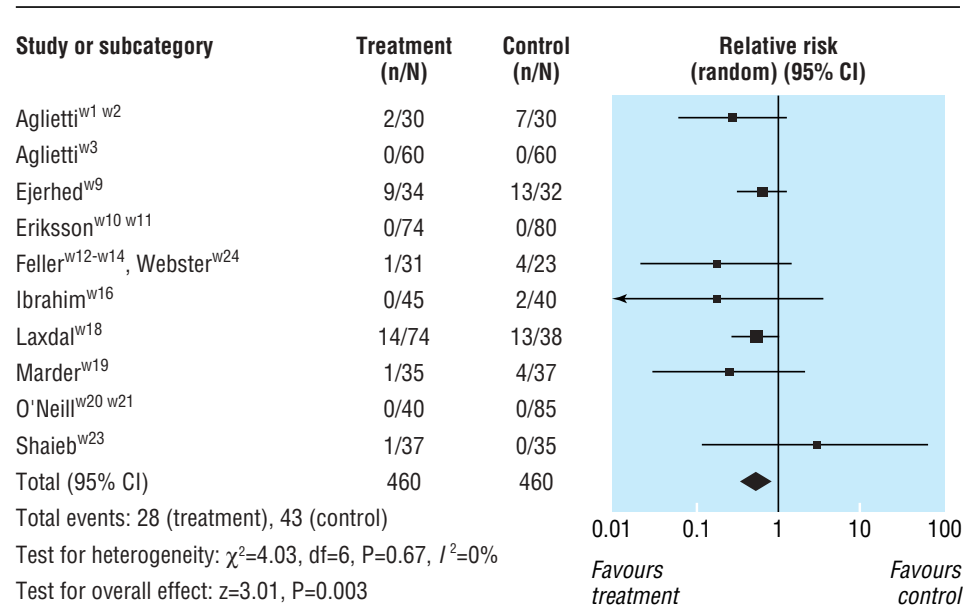

Fig 6 Loss of extension after reconstruction of the anterior cruciate ligament. Treatment refers to hamstring autografts; control refers to bone-patellar tendon-bone autografts

failure was 1.33 ( 0.73 to $2.44 ; \mathrm{P}=0.35$ ). The test for heterogeneity was not significant $(\mathrm{P}=0.99)$.

\section{Subgroup analyses}

Quantitative interaction tests on the effect of treatment based on study quality, randomisation status, and number of strands were not significant (table 3).

In studies using a four strand hamstring autograft (table 1), stability outcomes remained in favour of patients with patellar tendon reconstructions, but the difference between groups was not significant (table 2).

\section{Discussion}

Patients with hamstring autografts reported fewer anterior knee symptoms and extension deficits than patients with patellar tendon autografts, and we found no evidence that patellar tendon autografts provided better stability than four strand hamstring autografts.

\section{Knee stability}

Many factors during and after surgery can influence anterior tibial translation: cycling of the graft, degree of knee flexion and the tension applied to the graft at the time of fixation, bone to bone versus tendon to bone healing, and rehabilitation. ${ }^{13-17}$ To reduce confounding variables, authors standardised most of the procedures (surgical technique and rehabilitation) in both groups. However, these variables could have different effects on knee laxity in the two types of autograft even when they were distributed equally between groups, and the better outcome for knees reconstructed with patellar tendon autografts could have been overestimated owing to these methodological issues.

Stabilisation of the joint should have a protective effect against degenerative joint disease. ${ }^{18}$ However, to prevent later osteoarthritis, it seems more important to stop pivoting of the joint (pivot shift test) than to reduce anterior-posterior laxity (Lachman test and the instrumented measurement of knee laxity $)^{19}$; we found no difference between groups with regard to the pivot shift test.

\section{Knee morbidity}

Morbidity at the graft harvest site is the most important factor in the differences seen between the two groups. The decreased incidence of symptoms in the anterior knee when the graft is harvested from the contralateral side highlights the important part played by graft harvest in anterior knee pain. ${ }^{20}$ It has been argued that morbidity at the harvest site is lower by the end of the first year, but all studies had a follow-up of more than 12 months. ${ }^{21}$ Even if improvements in surgical techniques and rehabilitation programmes can reduce anterior knee symptoms after reconstruction using patellar tendon autografts, these patients are still prone to develop anterior knee symptoms and late patellofemoral osteoarthritis. ${ }^{22-24}$

The two main reasons for loss of mobility after anterior cruciate ligament surgery are impingement and capsulitis (arthrofibrosis). Technical errors that cause impingement should be

Table 3 Interaction tests to look for variations in effect of treatment in meta-analysis of trials to compare bone-patellar tendon-bone autografts with hamstring autografts for reconstruction of the anterior cruciate ligament

\begin{tabular}{|c|c|c|c|c|c|c|}
\hline Outcome & Relative risk $(95 \% \mathrm{Cl})$ & $P$ value & Test for heterogeneity & No of patients & No of studies & Interaction test \\
\hline \multicolumn{7}{|l|}{ Pivot test } \\
\hline Quality $\geq 3$ & 1.17 (0.86 to 1.59$)$ & 0.32 & 0.55 & 459 & 5 & 0.54 \\
\hline Quality <3 & 1.40 (0.87 to 2.26$)$ & 0.16 & 0.54 & 356 & 5 & \\
\hline Randomised & 1.34 (0.96 to 1.88$)$ & 0.09 & 0.43 & 497 & 6 & 0.44 \\
\hline Quasi-randomised & 1.09 (0.73 to 1.63$)$ & 0.67 & 0.79 & 318 & 4 & \\
\hline 4 strands & 1.13 (0.85 to 1.50$)$ & 0.41 & 0.83 & 703 & 8 & 0.16 \\
\hline$<4$ strands & 1.83 (1.0 to 3.35 ) & 0.05 & 0.33 & 112 & 2 & \\
\hline \multicolumn{7}{|l|}{ Anterior knee pain } \\
\hline Quality $\geq 3$ & 0.59 (0.42 to 0.82$)$ & 0.002 & 0.53 & 604 & 8 & 0.75 \\
\hline Quality $<3$ & 0.54 (0.35 to 0.84$)$ & 0.007 & 0.97 & 407 & 6 & \\
\hline Randomised & 0.60 (0.44 to 0.82$)$ & 0.001 & 0.84 & 653 & 9 & 0.51 \\
\hline Quasi-randomised & 0.49 (0.29 to 0.82$)$ & 0.007 & 0.85 & 358 & 5 & \\
\hline
\end{tabular}


distributed equally between the two groups. Development of arthrofibrosis after reconstruction has been much debated and results from an exaggerated inflammatory response, or is secondary to delayed mobilisation, infection, or sympathetic dystrophy. ${ }^{25}{ }^{26}$ Patients who have a patella tendon reconstruction are susceptible to anterior knee pain and synovitis, ${ }^{\mathrm{w} 13}$ and this correlates with the development of arthrofibrosis. ${ }^{27}$ Quadriceps weakness and inhibition ${ }^{\mathrm{w} 5} \mathrm{w13}$ w17 w21 and anterior knee symptoms after patella tendon reconstruction can result in delayed or inadequate rehabilitation and deferred recovery of full extension, which may cause permanent loss of extension. ${ }^{28} 29$

\section{Limitations of the study}

Many questions that could affect the results remain unanswered. The effect of medical professionals plays an important part in trials not investigating drugs - the results could have been biased if surgeons had more expertise in one of the two techniques. An expertise based randomised controlled trial might enhance the validity of such a comparison. ${ }^{30}$ Patients' characteristics (such as age, sex, level of activity, and weight) and technical issues (such as cycling of the graft, degree of knee flexion and graft tension when securing the graft, and fixation devices) cannot be analysed in a meta-analysis of aggregate patient data, and ideally data from individual patients should be analysed. ${ }^{31}$ We are currently investigating this.

\section{Conclusions}

Patients with hamstring autografts report fewer anterior knee symptoms and extension deficits than patients with patellar tendon autografts. This is important and should be taken into account when advising patients of certain ethnic origins and religions (for example, Asian people who often kneel or squat and Muslims who need to kneel for prayer $)^{\mathrm{w} 16}$ or patients who do sports (such as jumping) where extensor mechanisms are used extensively. ${ }^{32}$ The small improvement of stability in patellar tendon autografts compared with four strand hamstring autografts is of questionable importance for most patients and should be honestly discussed with patients who are more likely to benefit.

The poor methodological quality of the studies calls into question the robustness of the analyses, so it is difficult to make definitive conclusions. The methodological quality of surgical trials needs to be improved.

We thank S Abdulrazik, L Ejerhed, K Eriksson, J Feller, A Harilainen, K Jansson, J Kartus, G Laxdal, M Röpke, and K Webster who gave additional information on published and unpublished trials and helped in the literature search. We also thank A Anderson, D Brand, E Eriksson, K Eriksson, J Feller, M Hantes, M Marcacci, H Roos, R Smith, and J Webb who

\section{What is already known on this topic}

Hamstring autografts and patellar tendon autografts are the two preferred options for reconstruction of knees with damaged anterior cruciate ligaments

The stability and morbidity outcomes of these autografts are unclear

\section{What this study adds}

Patients with hamstring autografts report fewer anterior knee symptoms and extension deficits than patients with patellar tendon autografts

The stability of patellar tendon autografts and four strand hamstring autografts is similar helped in the literature search. Their participation does not necessarily mean that they agree with the conclusions of our study.

Contributors: DJB conceived, designed, and developed the protocol and search strategy for the review; contacted authors, journals, and organisations; identified and extracted data from included trials; analysed and interpreted the results; and wrote the manuscript. CT identified and extracted data from included trials and participated in the analysis and interpretation of results and revision of the manuscript. SK analysed and interpreted the results and participated in the drafting and revision of the manuscript. PJS participated in the analysis and interpretation of results and in the drafting and revision of the manuscript. RSN contributed to the conception, design, and development of the protocol, the interpretation of the results, and the drafting and revision of the manuscript. DJB is guarantor.

Funding: None.

Competing interests: None declared.

Ethical approval: Not required.

1 Miyasaka KC, Daniel DM, Shore ML, Hirsham P. The incidence of knee ligament injuries in the general population. Am J Knee Surg 1991;4:3-8.

2 American Academy of Orthopaedic Surgeons. Repair of anterior cruciate ligament (ACL) tears. www.aaos.org/wordhtml/research/stats/ACLRepairfacts.htm (accessed 3 Aug tears.

3 Fithian DC, Paxton LW, Goltz DH. Fate of the anterior cruciate ligament-injured knee. Orthop Clin North Am 2002;33:621-36.

4 Sherman OH, Banffy MB. Anterior cruciate ligament reconstruction: which graft is best? Arthroscopy 2004;20:974-80.

5 Jones KG. Reconstruction of the anterior cruciate ligament using the central one-third of the patellar ligament. J Bone Joint Surg Am 1970;52:838-9.

6 Marx RG, Jones EC, Angel M, Wickiewicz TL, Warren RF. Beliefs and attitudes of members of the American Academy of Surgeons regarding the treatment of anterior cruciate ligament. Arthroscopy 2003;19:762-70.

7 Lipscomb AB, Johnston RK, Snyder RB. The technique of cruciate ligament reconstruction. Am J Sports Med 1981;9:77-81.

8 Carter TR, Edinger S. Isokinetic evaluation of anterior cruciate ligament reconstruction: hamstring versus patellar tendon. Arthroscopy 1999;15:169-72.

9 Forster MC, Forster IW. Patellar tendon or four-strand hamstring? A systematic review of autografts for anterior cruciate ligament reconstruction. Knee 2005;12:225-30.

10 Yunes M, Richmond JC, Engels EA, Pinczewski LA. Patellar versus hamstring tendons in anterior cruciate ligament reconstruction: a meta-analysis. Arthroscopy 2001;17:24857.

11 Francis A, Thomas RD, McGregor A. Anterior cruciate ligament rupture: reconstruction surgery and rehabilitation. A nation-wide survey of current practice. Knеe 2001;8:13-8.

12 Malanga GA, Andrus S, Nadler SF, McLean J. Physical examination of the knee: a review of the original test description and scientific validity of common orthopedic review of the original test description and scien
tests. Arch Phys Med Rehabil 2003;84:592-603.

13 Arnold MP, Lie DT, Verdonschot N, de Graaf R, Amis AA, van Kampen A. The remains of anterior cruciate ligament graft tension after cyclic knee motion. Am J Sports Med 2005;33:536-42.

14 Fleming BC, Abate JA, Peura GD, Beynnon BD. The relationship between graft tensioning and the anterior-posterior laxity in the anterior cruciate ligament reconstructed goat knee. J Orthop Res 2001;19:841-4.

15 Nicholas SJ, D’Amato MJ, Mullaney MJ, Tyler TF, Kolstad K, McHugh MP. A prospectively randomized double-blind study on the effect of initial graft tension on knee stability after anterior cruciate ligament reconstruction. Am J Sports Med 2004:32:1881-6.

16 Tomita F, Yasuda K, Mikami S, Sakai T, Yamazaki S, Tohyama H. Comparisons of intraosseous graft healing between the doubled tendon graft and the bone-patellar tendonosseous graft healing between the doubled tendon graft and the bone-patella
bone graft in anterior ligament reconstruction. Arthroscopy 2001;17:461-76.

17 Bynum EB, Barrack RL, Alexander AH. Open versus closed chain kinetic exercises after anterior ligament reconstruction. A prospective randomized study. Am J Sports Med 1995;23:401-6.

18 British Orthopaedic Association, British Association for Surgery of the Knee, and British Orthopaedic Sports Trauma Association. ACL reconstruction: best practice. www.boa.ac.uk/PDF\%20files/BASK/ACL\%20best\%20practice.pdf (accessed 11 Dec 2005).

19 Jonsson H, Riklund-Ahlstrom K, Lind J. Positive pivot shift after ACL reconstruction predicts later osteoarthrosis: 63 patients followed 5-9 years after surgery. Acta Orthop Scand 2004;75:594-9.

20 Mastrokalos DS, Springer J, Siebold R, Paessler HH. Donor site morbidity and return to the preinjury activity level after anterior cruciate ligament reconstruction using ipsilatthe preinjury activity level after anterior cruciate ligament reconstruction using ipsilat-
eral and contralateral patellar tendon autograft: a retrospective, nonrandomized study. eral and contralateral patellar te
Am J Sports Med 2005;33:85-93.

21 Rubinstein RA Jr, Shelbourne KD, VanMeter CD, McCarroll JC, Rettig AC. Isolated autogenous bone-patellar tendon-bone graft site. Am J Sports Med 1994;22:324-7.

22 Tsuda E, Okamura Y, Ishibashi Y, Otsuka H, Toh S. Techniques for reducing anterior knee symptoms after anterior cruciate ligament reconstruction using a bone-patellar tendon-bone autograft. Am J Sports Med 2001;29:450-6.

23 Shelbourne KD, Trumper RV. Preventing anterior knee pain after anterior cruciate ligament reconstruction. Am J Sports Med 1997;25:41-7.

24 Jarvela T, Paakkala T, Kannus P, Jarvinen M. The incidence of patellofemoral osteoarthritis and associated years after anterior cruciate ligament reconstruction with a tendon-bone autograft. Am J Sports Med 2001;29:18-24.

25 Bosch U, Zeichen J, Skutek M. Haeder L, van Griensven M. Arthrofibrosis is the result of a T cell mediated immune response. Knee Surg Sports Traumatol Arthrosc of a T cell

26 Mayr HO, Weig TG, Plitz W. Arthrofibrosis following ACL reconstruction-reasons and outcome. Arch Orthop Trauma Surg 2004;124:518-22. 
27 Kartus J, Magnusson L, Stener S, Brandsson S, Eriksson BI, Karlsson J. Complications following arthroscopic anterior cruciate ligament reconstruction. A 2-5-year follow-up of 604 patients with special emphasis on anterior knee pain. Knee Surg Sports Traumatol Arthrosc 1999;7:2-8.

28 Mikkelsen C, Cerulli G, Lorenzini M, Bergstrand G, Werner S. Can a post-operative brace in slight hyperextension prevent extension deficit after anterior cruciate ligament reconstruction? A prospective randomised study. Knee Surg Sports Traumatol Arthros 2003;11:318-21.

29 Noyes FR, Berrios-Torres S, Barber-Westin SD, Heckmann TP. Prevention of permanent arthrofibrosis after anterior cruciate reconstruction alone or combined with associated procedures: a study in 443 knees. Knee Surg Sports Traumatol Arthrosc 2000;8:196-206.

30 Devereaux PJ, Bhandari M, Clarke M, Montori VM, Cook DJ, Yusuf S, et al. Need for expertise based randomised controlled trials. BMJ 2005;330:88.

31 Lyman GH, Kuderer NM. The strengths and limitations of meta-analyses based on aggregate data. BMC Med Res Methodol 2005;5:14.

32 Gobbi A, Mahajan S, Zanazzo M, Tuy B. Patellar tendon versus quadrupled bone-semitendinosus anterior cruciate ligament reconstruction: a prospective clinical investigation in athletes. Arthroscopy 2003;19:592-601.

(Accepted 23 February 2006)

doi $10.1136 / \mathrm{bmj} .38784 .384109 .2 \mathrm{~F}$

Service de chirurgie orthopédique et traumatologique, Hôpital Cochin, Assistance Publique-Hôpitaux de Paris, 75679 Paris, France
David J Biau specialist registrar (orthopaedic and trauma surgery)

Département de biostatistique et informatique médicale, Hôpital Saint-Louis, Assistance Publique-Hôpitaux de Paris, 75475 Paris

Caroline Tournoux specialist registrar (statistics and public health)

Sandrine Katsahian consultant (statistics and public health)

Service de chirurgie orthopédique et traumatologique, Hôpital Lariboisière, Assistance Publique-Hôpitaux de Paris, 75010 Paris

Rémy S Nizard professor (orthopaedic and trauma surgery)

Orthopaedics and Trauma, Princess Elizabeth Orthopaedic Centre, Royal Devon and Exeter Hospital, Exeter EX2 5DW

Peter J Schranz clinical director (orthopaedic and trauma surgery)

Correspondence to: D Biau djmbiau@yahoo.fr

\section{Amendment}

This is version 2 of the paper. In this version, table 1 has been corrected. The units for the column heading "Mean follow-up" have been changed from days to months. 